\title{
CULTURA ORGANIZACIONAL NO SETOR PÚBLICO: UM ESTUDO JUNTO A UM DEPARTAMENTO ADMINISTRATIVO DE UMA UNIVERSIDADE FEDERAL BRASILEIRA
}

\section{ORGANIZATIONAL CULTURE IN THE PUBLIC ADMINISTRATION: A STUDY IN ADMINISTRATIVE DEPARTMENT OF BRAZILIAN FEDERAL UNIVERSITY}

Recebido 11/01/2010

Aceito 16/09/2011

Rodrigo Rorato e Evandro Dotto Dias

\section{RESUMO}

A cultura organizacional é um tema complexo e constantemente em estudo por especialistas e pesquisadores de todo o mundo, pela sua relevância na compreensão do funcionamento das organizações. No entanto, esse tipo de estudo ainda não foi totalmente difundido nas organizações públicas brasileiras, principalmente em universidades federais. Por isso, este trabalho tem como objetivo geral identificar a cultura organizacional sob os pontos de vista pessoal e institucional em um departamento administrativo da Universidade Federal de Santa Maria, através de uma relação com os quatro deuses gregos (Zeus, Apolo, Atena e Dionísio) que refletem a forma como são conduzidas as políticas e estratégias em uma organização, segundo Handy (1994). Por meio de um levantamento realizado com os funcionários do referido departamento, os resultados obtidos permitiram a conclusão de que há a predominância da cultura organizacional do tipo Apolo na ótica institucional e do tipo Atena na ótica pessoal. Um comparativo feito entre as características predominantes em cada uma dessas culturas mostrou uma divergência entre os anseios dos colaboradores e a forma como a organização age no seu dia a dia, conforme os pontos abordados pela pesquisa e apresentados na análise dos resultados.

Palavras-chave: Administração pública. Gestão de pessoas. Cultura organizacional. Universidade federal. Deuses da administração. 


\section{ABSTRACT}

The organizacional culture is a complex subject and that constantly it comes being studied for specialists and researchers of the whole world, for the fact of its relevance in the understanding of the functioning of the organizations. However, this type of study not yet total was spread out in the Brazilian public organizations, mainly in federal universities. Therefore, the present work has as objective generality to identify to the organizacional culture under the personal and institucional points of view in an managemental department of the Federal University of Saint Maria, through a comparison with four deuses Greek (Zeus, Apolo, Atena and Dionísio) that they reflect the form as the politics and strategies in an organization are lead, according to Handy study (1994). By means of a survey carried through with the employees of the related department, the gotten results had allowed the conclusion of that it has the predominance of the organizacional culture of the Apolo type in the institucional optics and of the Atena type in the personal optics, where a made comparative degree enter the predominant characteristics in each one of these cultures showed a divergence enter the yearnings of the collaborators and the form as the organization acts day-by-day in its, as the points boarded for the research and presented in the analysis of the results.

Keywords: Public administration. Management people. Organizational culture. Federal university. Gods of the administration.

\section{INTRODUÇÃO}

Atualmente, as mudanças ligadas à globalização, flexibilização de processos, competitividade empresarial e novas formas de organização do trabalho têm lugar garantido na análise daqueles que atuam ou estudam as organizações em todos os setores. No contexto das organizações públicas, essas alterações refletem a luta de forças resultante da necessidade de mudanças e inovações no mundo contemporâneo versus a cadência e a burocracia arraigadas no sistema público tradicional. Isso fica ainda mais evidente quando se observa o funcionamento das Instituições Federais de Ensino Superior (IFES), onde o ensino, a pesquisa e a extensão buscam o aperfeiçoamento dos processos de gestão, mas encontram obstáculos burocráticos na sua efetivação.

Na maioria dos países em fase de desenvolvimento, inclusive no Brasil, as IFES tiveram que ser ampliadas ou constituídas integralmente em um curto espaço de tempo. Essas ampliações consistiram na busca da melhoria da qualidade nos processos administrativos, através de uma administração universitária voltada para a eficiência organizacional, ou seja, a preocupação estaria na relação entre os resultados obtidos com os recursos disponíveis.

Já a eficácia na gestão (que deveria levar em conta a relação entre os resultados obtidos e os objetivos pretendidos), ficou caracterizada apenas pela avaliação da finalidade de se ter as pessoas executando tarefas, evitando conflitos e dispersão dos recursos disponíveis (RIZZATTI, 2002). Sendo assim, uma das perspectivas para a mudança desse panorama seria a partir da avaliação da cultura organizacional, que é a proposta de estudo neste artigo.

A cultura é um dos pontos mais importantes na compreensão das ações humanas, funcionando como um padrão coletivo que identifica os grupos, suas maneiras de perceber, pensar, sentir e agir. Segundo Pires e Macedo (2006), mais do que um conjunto de regras, de hábitos e de artefatos, a cultura significa a construção de significados partilhados pelo conjunto de pessoas pertencentes ao mesmo grupo social.

Por isso, neste artigo são apresentados os resultados de um trabalho cujo objetivo geral é identificar a(s) cultura(s) organizacional(is) em um departamento administrativo de uma Instituição Federal de Ensino Superior, a partir da comparação com os quatro deuses gregos que influenciam a administração das organizações (Zeus, Apolo, Atena e Dionísio), de acordo com 
Handy (1994). A justificativa estaria na necessidade de proporcionar melhores subsídios para a tomada de decisões dos gestores da instituição e para a realização de futuros estudos nessa área. Além disso, os objetivos específicos deste estudo são: (a) analisar as principais características culturais predominantes no referido departamento e (b) verificar a existência ou não de discordância entre a cultura da instituição e a cultura proposta pelos empregados. Para isso, foi realizada uma pesquisa do tipo survey junto ao departamento, onde os funcionários avaliaram alguns pontos importantes relativos ao ambiente de trabalho, os quais acabaram por expressar o perfil da cultura predominante na perspectiva pessoal e organizacional.

Assim, o artigo apresenta-se iniciando pela introdução, seguido pelo referencial teórico relativo à área de pesquisa, pela caracterização do objeto de estudo, pela metodologia, pela análise e discussão dos resultados, bem como pelo encerramento com a conclusão obtida e a bibliografia consultada.

\section{REFERENCIAL TEÓRICO}

Uma função da cultura organizacional é distinguir uma organização de outras e de seu ambiente, proporcionando, de certa forma, uma identidade externa (NORBERTO, 2009). Assim, diversos pesquisadores ao longo do tempo desenvolveram inúmeros conceitos sobre o assunto, de modo a convergir em um ponto: a cultura é uma questão interpretativa de cada organização. No caso do setor público, as instituições, em função de sua uniformidade administrativa, apresentam culturas similares, sendo que, muitas vezes, as características identificadas na cultura de uma organização podem equivaler à de outra.

\subsection{Cultura organizacional na administração pública}

Falar em cultura implica falar sobre a capacidade de adaptação do individuo à realidade do grupo no qual está inserido. Assim, Fleury e Fischer (1989) afirmam que a cultura é concebida como um conjunto de princípios e pressupostos básicos expressos em elementos simbólicos, que sua capacidade de atribuir significados e construir uma identidade tanto age como um elemento de consenso, como oculta e instrumentaliza as relações de dominação em um grupo ou organização.

Nessa perspectiva, Coda (1997), quando realizou um estudo em várias empresas brasileiras, concluiu que, do ponto de vista dos trabalhadores, as organizações brasileiras sequer estão conseguindo tornar claro seus princípios e praticar uma gestão compatível com seu próprio funcionamento, principalmente aquelas do setor público. Em seu estudo, os gerentes e chefes foram frequentemente criticados pelos funcionários, de modo que esse sentimento veio a refletir um grande problema de liderança e de projeto organizacional, que acabaria por impactar negativamente o planejamento estratégico de tais organizações.

Conforme Pires e Macedo (2006), a cultura da maioria das organizações públicas, no Brasil, leva essas organizações a burocracias tradicionais que, além de terem se tornado complexas, com atributos centralizadores e estruturas rígidas, não têm sido planejadas para o atendimento das necessidades dos cidadãos, ou para a efetiva eficácia na prestação dos serviços.

Nesse contexto, Meirelles (1998 apud PINHEIRO, 2000) afirma que o sistema burocrático presente na maioria das autarquias e fundações públicas preocupa-se principalmente em 
fazer valer um modelo de gestão voltado à eficiência, isto é, o foco do sistema estaria apenas na obrigação de que o agente público tem em realizar suas atribuições com presteza, racionalidade, economicidade e rendimento funcional. Já as empresas públicas que atuam no mercado com a comercialização de produtos/serviços, ainda segundo o autor, são as poucas, no setor público, que fazem um uso maior de modelos de decisão voltados à avaliação da eficácia de sua gestão, ou seja, levam em conta a análise do resultado obtido dentro dos objetivos estipulados. Essa ideia pode ser mais bem compreendida pelo esquema apresentado na figura 1.

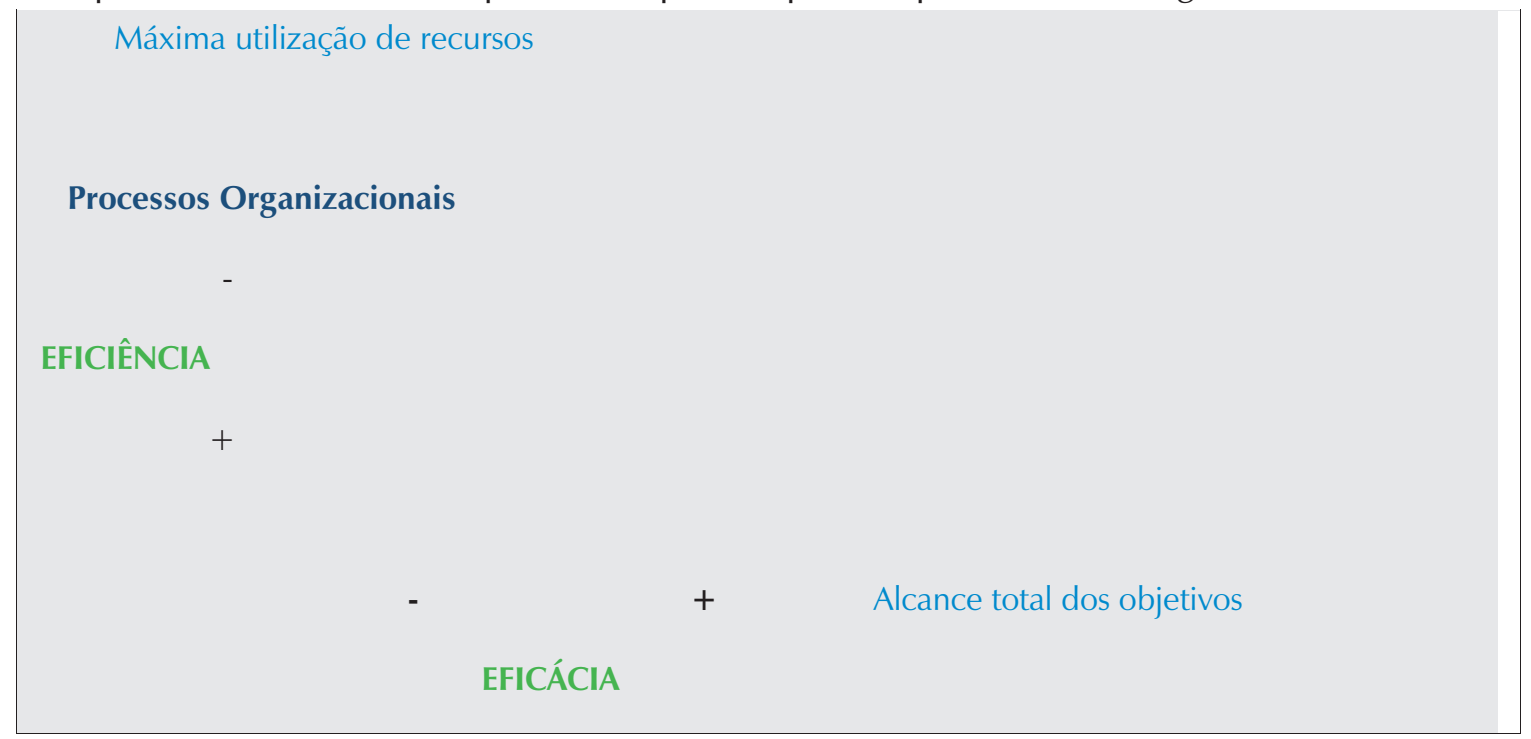

Figura 1 - Relação entre eficácia e eficiência. Fonte: Adaptada de Meirelles (1998 apud PINHEIRO, 2000)

Em vista disso, Castor e José (1998) inferem que a história da Administração Pública brasileira é uma repetição monótona da luta da burocracia ritualista, centralizadora, ineficaz e adversa a mudanças contra as correntes modernizantes das alas política e empresarial. Isso fica evidente quando Guimarães (2000) afirma que o desafio que se coloca frente às organizações públicas é o de transformar estruturas burocráticas, hierarquizadas e inclinadas a um processo de insulamento em organizações flexíveis e empreendedoras. Por isso, ainda segundo o autor, o delineamento do perfil cultural de um órgão público poderia contribuir muito para um diagnóstico do ambiente de trabalho e do desempenho organizacional, com vistas à melhoria da qualidade do produto/serviço oferecido.

\subsection{Modelos culturais nas organizações}

Na dinâmica social de uma organização, a descrição dos elementos que constituem o perfil da cultura, a forma como eles funcionam e as mudanças comportamentais que eles provocam são as maneiras de dar ao assunto uma forma mais fácil de compreensão. No entanto, a dificuldade de consenso na descrição da cultura nas organizações é tão notória que alguns pesquisadores têm privilegiado diferentes aspectos da questão. Um desses aspectos é abordado por Handy (1994), que, em uma das mais competentes tentativas de análise e explicação do comportamento organizacional, utilizou uma forma peculiar de definir a cultura das organiza- 
ções. Para o autor, a cultura organizacional está dividida em duas situações: ponto de vista da empresa e ponto de vista das pessoas que trabalham nessa empresa. Ademais, o autor afirma que existem quatro tipos de "cultura-organização", assim como os Deuses da Grécia Antiga, que simbolizam as filosofias de administração, tais como: Organização-Zeus (cultura de clube), Organização-Apolo (cultura de função), Organização-Atena (cultura de tarefa) e OrganizaçãoDionísio (cultura existencial). É importante ressaltar que, através da análise desses modelos culturais, algumas pesquisas foram realizadas e acabaram por validar a proposta de Handy (1994), como, por exemplo, os estudos desenvolvidos por Freitas (1991), Chatman (1989) e Gomide Júnior e Martins (1997).

\subsubsection{Cultura Zeus}

Segundo Handy (1994), a cultura Zeus ou cultura de clube tem uma característica centralizadora marcante, com um processo de tomada de decisões que é muito rápido e que transcende facilmente os padrões estabelecidos, além de que utiliza pouca documentação e depende de redes de amizades, que podem parecer fechadas e nepotistas. Nessa cultura, o aprendizado geralmente é secreto, os membros aprendem com erros e tentativas e o que conta é o controle dos recursos e o carisma pessoal, além do poder financeiro ser altamente valorizado pelos indivíduos. Nas pequenas empresas familiares em geral, esse perfil fica bem evidente.

\subsubsection{Cultura Apolo}

Handy (1994) preconiza que a cultura Apolo ou cultura de função assume que o homem é racional e que tudo pode ser analisado de maneira lógica (método burocrático). Essa cultura se vale de que o dia de amanhã será igual ao hoje e ao ontem, seus membros não se adaptam facilmente a mudanças e há pouco incentivo à criatividade. Para a organização Apolo, não importa quem são os indivíduos, e sim a garantia de que as funções sejam desempenhadas para manter todo o sistema organizacional em funcionamento. Em geral, organizações do setor público apresentam essas características.

\subsubsection{Cultura Atena}

Na cultura Atena, os indivíduos se preocupam com a solução contínua e bem sucedida de problemas. Nessa cultura, a organização é dinâmica (em constante adaptação), seus membros gostam de desafios e procuram respostas às incertezas. Handy (1994, p. 28) enfatiza que "as organizações dessa natureza têm altos custos", pois, na resolução de problemas, é quase inevitável o erro nas primeiras tentativas e, mesmo que a solução seja alcançada rapidamente, o dispêndio será expressivo. Um exemplo disso está nas empresas do setor tecnológico, que fazem altos investimentos em pesquisa e desenvolvimento a fim de buscar soluções inteligentes e novos produtos, o que acaba por fomentar uma gestão moderna, com base em um perspectiva de organização que aprende.

\section{- CULTURA DIONÍSIO}

A cultura Dionísio parte do princípio de que a organização existe para auxiliar o indivíduo a realizar seus objetivos. Essa cultura é ótima onde o recurso principal de uma organização é o talento, a habilidade ou a competência de um membro e/ou sua equipe. Na organização de 
Dionísio, os indivíduos não estão interessados em fazer carreira, e sim obter novas experiências e desafios e satisfazer seus desejos. Conforme Handy (1994), a profissão vem em primeiro lugar em uma organização Dionísio. As organizações formadas por profissionais autônomos representam bem as características dessa cultura, onde o foco do negócio está na prestação de serviços em que o profissional é especialista, como escritórios de consultoria, advocacia, consultórios médicos etc..

\section{METODOLOGIA}

Quanto aos procedimentos técnicos e ao objetivo de estudo, este trabalho é considerado como uma pesquisa de levantamento de caráter descritivo, visto que descreve o perfil da cultura organizacional no Departamento de Registro e Controle Acadêmico (DERCA) da Universidade Federal de Santa Maria (UFSM) sob diferentes óticas. A realização de um levantamento descritivo, segundo Vergara (2006), possibilita a exposição das características de determinada população, sem o compromisso de explicar os fenômenos que descreve, embora sirva de base para tal explicação.

Dessa forma, a pesquisa foi realizada no segundo semestre de 2009 com o universo composto pelos 24 funcionários que trabalham no referido departamento. Quanto à abordagem, este estudo apresenta enfoque quantitativo, pelo fato de que visa mensurar a intensidade de atributos relativos à cultura existente na organização. De acordo com Terence e Escrivão Filho (2006), a pesquisa quantitativa em ciências sociais permite a mensuração de opiniões, hábitos e atitudes em um universo, com base em uma fundamentação teórica durante o desenvolvimento de hipóteses e variáveis de pesquisa, de modo a tornar mais precisos os resultados de um estudo.

O instrumento utilizado para a coleta de dados foi um questionário padrão, com nove questões objetivas relativas à cultura organizacional, aplicado a cada um dos colaboradores, onde havia quatro alternativas de resposta em cada questão, mas podia ser escolhida somente uma opção. Inicialmente, o respondente se avaliava enquanto funcionário e, em um segundo momento, avaliava o comportamento da organização. Neste estudo, os dados foram tabulados em microcomputador e empregou-se a análise gráfica percentual para avaliação dos resultados.

Assim, o trabalho baseou-se na técnica de definição da cultura organizacional proposta por Handy (1994), que aborda a existência de quatro tipos de cultura no ambiente de trabalho, tais como: Cultura Zeus, Cultura Apolo, Cultura Atena e Cultura Dionísio (conforme abordado no referencial teórico). Desse modo, cada uma das alternativas de resposta contidas no questionário continha características pertinentes a cada uma das culturas citadas anteriormente. A opção que apresentou o maior percentual de respostas correspondeu ao tipo de cultura organizacional predominante no DERCA/UFSM em cada perspectiva de avaliação: ponto de vista pessoal e ponto de vista organizacional. É importante ressaltar que, por limitações de acesso e disponibilidade de tempo para a elaboração de uma pesquisa mais ampla, este estudo ficou delimitado à análise da população de um determinado departamento administrativo (DERCA), onde os resultados obtidos podem não expressar o perfil da cultura organizacional predominante na instituição como um todo, pois, segundo Estrada (2001), uma universidade está dividida pelas atividades meio (administração do ensino) e atividades fim (ensino, pesquisa e extensão), nas quais pode haver culturas diferentes. Portanto, a pesquisa apresentada neste artigo está limitada à apresentação do perfil da cultura organizacional predominante em uma das atividades meio da Universidade Federal de Santa Maria, onde está inserido o Departamento de Registro e Controle Acadêmico. 


\section{OBJETO DE ESTUDO}

Com a devida autorização dos dirigentes, a presente pesquisa foi realizada no Departamento de Registro e Controle Acadêmico (DERCA) da Universidade Federal de Santa Maria (UFSM), o qual é um órgão executivo da administração central responsável pela gestão acadêmica da instituição (autarquia), composta por mais de duzentos cursos de graduação e pósgraduação, que se encontram em constante expansão em virtude dos planos de desenvolvimento educacional promovidos pelo Ministério da Educação.

O DERCA é constituído hierarquicamente por três coordenadorias, dividas em nove núcleos, subdivididos em seis seções, que atendem às solicitações da comunidade acadêmica e do público em geral, com a emissão de documentos escolares, prestando informações e fazendo com que os agentes acadêmicos cumpram com as normativas internas e o calendário letivo da instituição. Outrossim, apresenta, em seu quadro funcional, uma equipe multiprofissional, com diferentes qualificações, o que permitiu uma ampla visão da cultura organizacional nesse setor. Além de sua relevância institucional, o DERCA passa por uma fase de mudanças, tanto por questões de aposentadoria e ingresso de funcionários como por questões de caráter político, tecnológico e de reestruturação funcional, que permitiram uma contribuição expressiva das

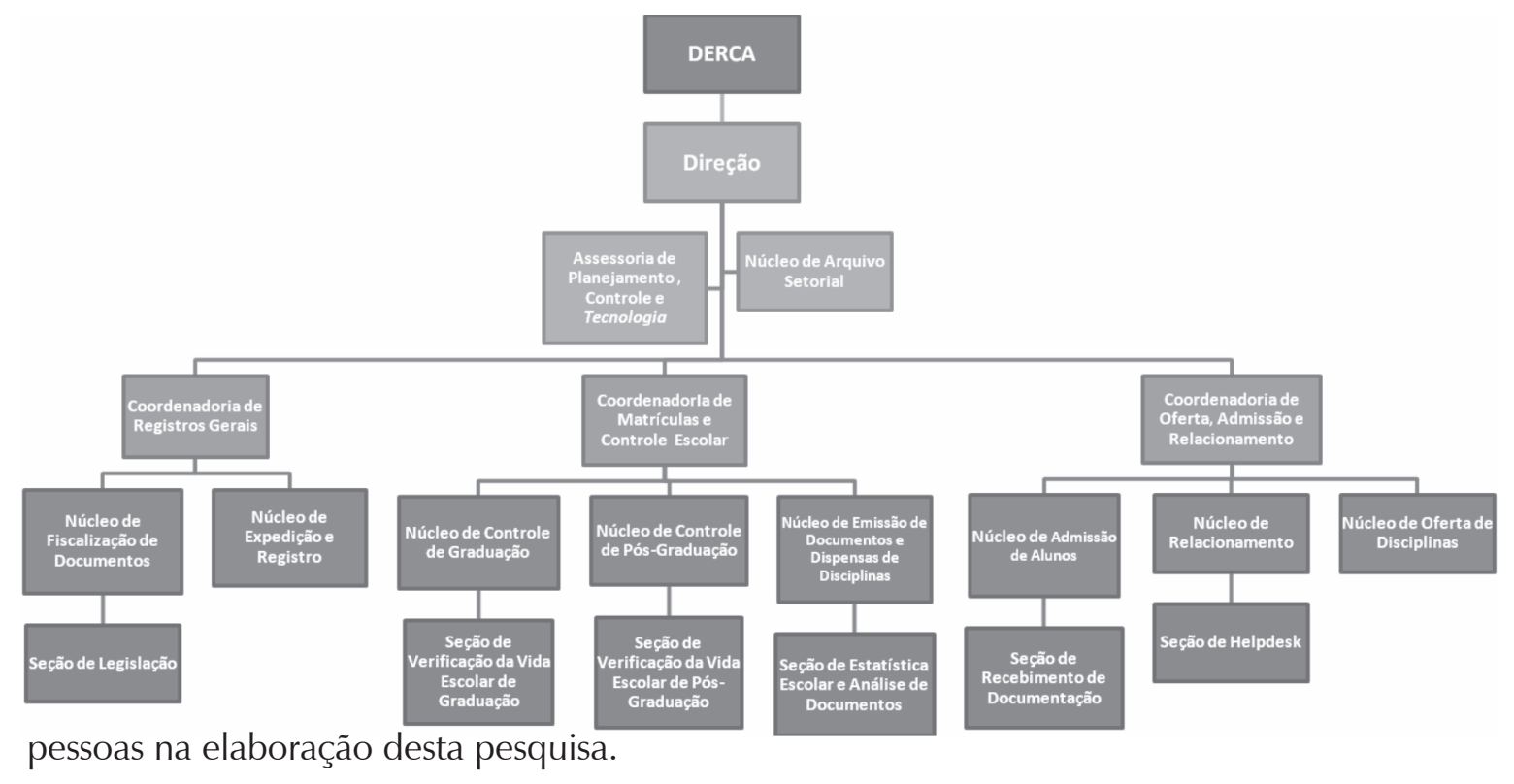

Figura 2- Organograma do DERCA. Fonte: Adaptada do Regimento Geral da UFSM (1988)

\section{APRESENTAÇÃO E ANÁLISE DOS RESULTADOS}

Dos tipos de cultura definidos anteriormente, os resultados da pesquisa mostram que, do ponto de vista da opinião pessoal dos colaboradores, ou seja, daquilo que os colaboradores esperariam que fosse a realidade, há o predomínio de aspectos da cultura Atena (36\%), e. no modo como a organização age no seu dia a dia (ponto de vista organizacional), predominam 


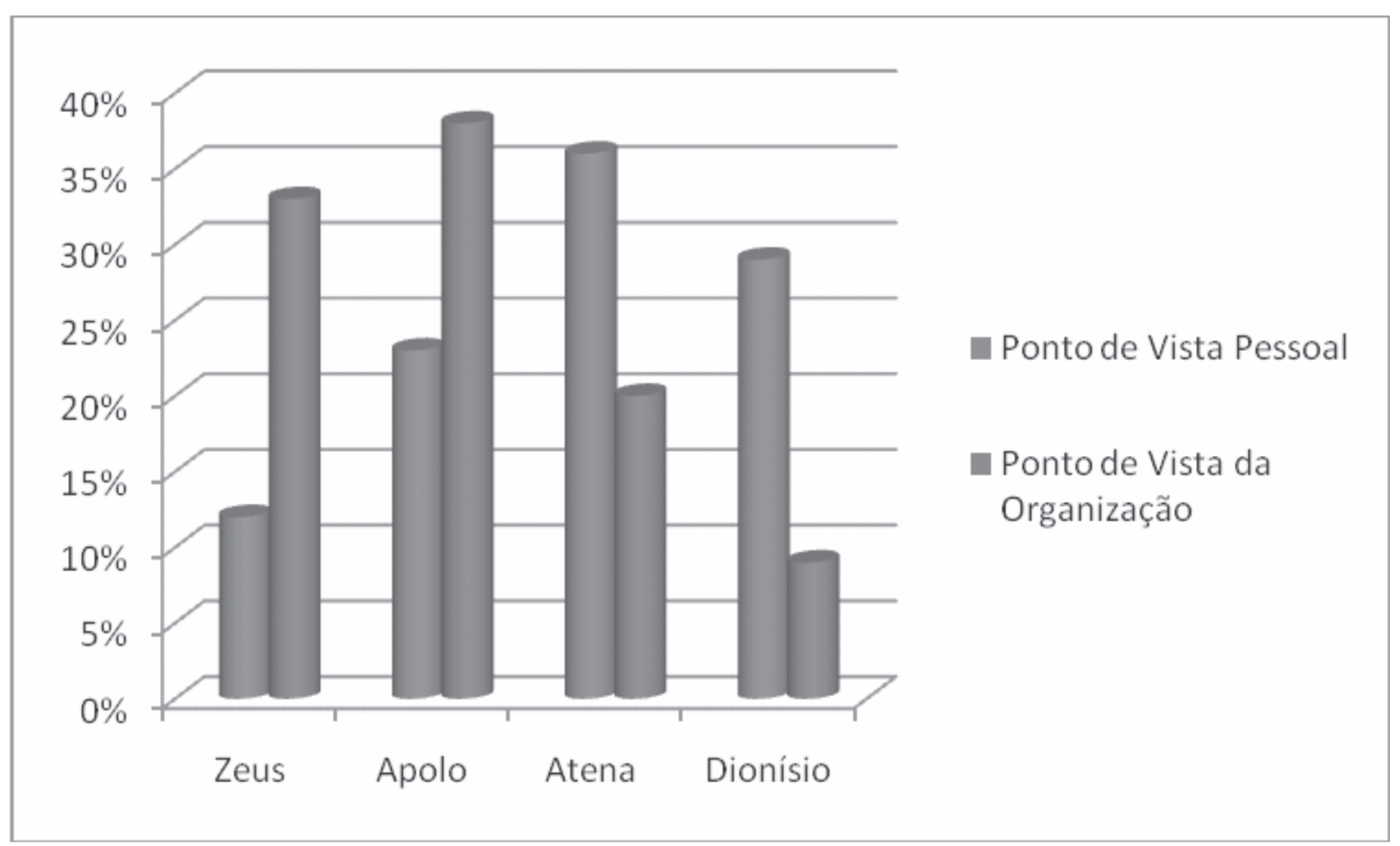

características da cultura Apolo (38\%), conforme os valores apresentados na figura 3.

Figura 3 - Percentual dos tipos de cultura predominantes no DERCA sob diferentes óticas

Observa-se que os aspectos da Cultura Zeus ou cultura de clube também apresentaram um percentual considerável em relação ao ponto de vista da organização (cerca de 33\%), os quais demonstram que, em setores específicos do departamento, tal perfil pode estar vigorando ou começando a surgir na relação entre as pessoas (entre chefias e subordinados). Do ponto de vista pessoal, a Cultura Dionísio também obteve um valor expressivo, representando a opinião de cerca $28 \%$ dos pesquisados, ou seja, também há algumas pessoas querendo que a entidade trate seus colaboradores conforme os princípios relativos a essa cultura. A análise gráfica mostra que, no modo como a organização age no cotidiano, imperam estilos de gestão bastante conservadores, como os da culturas Apolo e Zeus, enquanto os funcionários demonstram apreço por estilos mais flexíveis, propostos pelas culturas Atena e Dionísio.

Essa avaliação revela a existência de divergência entre os anseios dos funcionários e as políticas praticadas pela universidade, de maneira que a cultura existente na organização não corresponde plenamente àquela que os colaboradores acreditam que seja coerente com as suas aspirações.

Ademais, os resultados corroboram a conclusão obtida por Coda (1997), que mostra os problemas enfrentados principalmente pelas organizações do setor público, com relação à satisfação de seus funcionários no local de trabalho. Além disso, essa situação leva a crer que a produtividade dos colaboradores está aquém de seu potencial, visto que a organização pode não estar motivando-os, a qual está intimamente relacionada à congruência de expectativas e de afinidade de interesses; aspectos, esses, que integram a cultura organizacional (FLEURY; FISCHER, 1989).

No quadro 1, é possível detalhar melhor essa divergência, comparando as características culturais predominantes no departamento em estudo, segundo Handy (1994). 


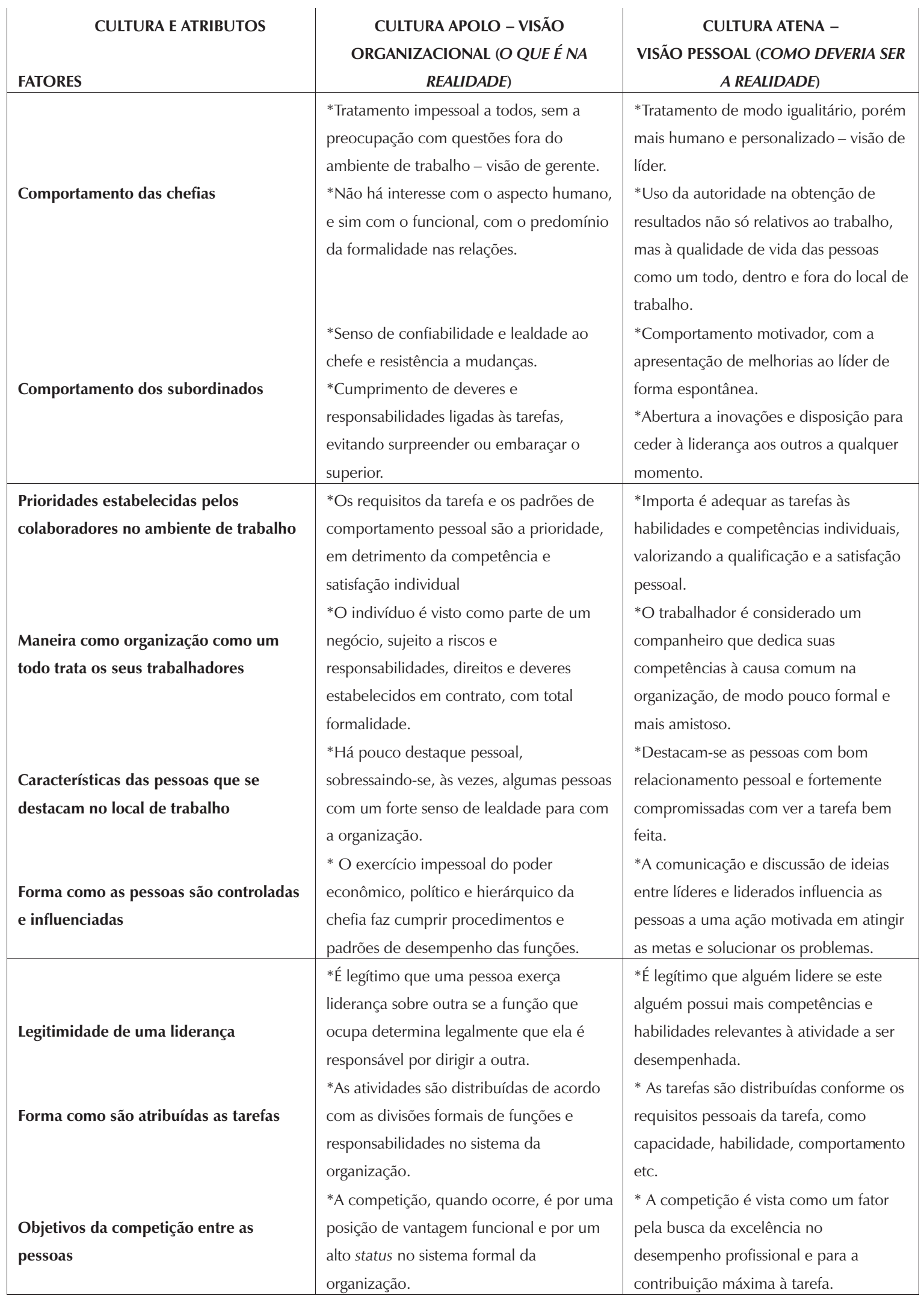

Quadro 1 - Relação das características culturais predominantes no DERCA/UFSM, conforme os fatores abordados pela pesquisa

Rev. Adm. UFSM, Santa Maria, v. 4, n. 3, p. 341-351 set./dez. 2011 
Como se nota no quadro, as características da Cultura Apolo ratificam a ideia apresentada anteriormente de que a UFSM, por ser uma organização pública sob a forma de autarquia, apresenta uma estrutura gerencial centralizadora e voltada mais à eficiência do que à eficácia na prestação de seus serviços. A Cultura Apolo tem essa característica marcante, pois mostra o reflexo da burocracia na gestão dos processos, através da racionalização estrutural, estática de cargos, e da impessoalidade e previsibilidade nas relações, sem motivar o desafio profissional, a competência individual e coletiva, a flexibilidade gerencial e o comprometimento pessoal com o trabalho a ser executado, que estão entre os principais atributos da cultura Atena, sugerida pelos colaboradores.

\section{CONCLUSÃO}

Dentro da proposta apresentada e das limitações desta pesquisa, conclui-se que a cultura organizacional predominante no DERCA/UFSM, do ponto de vista da organização (de como é na realidade), é a Cultura Apolo ou cultura de função, que se caracteriza pela eficiência nos processos (racionalidade e economicidade), preocupação restrita a aspectos do trabalho, tratamento impessoal e resistência a mudanças organizacionais; e, do ponto de vista das pessoas (de como deveria ser a realidade), há a predominância da Cultura Atena ou cultura de tarefa, que se caracteriza pela eficácia nas tarefas (foco em resultados), preocupação com a satisfação e relacionamento pessoal, estímulo ao empreendedorismo, flexibilidade de decisões e criatividade. Isso revela a existência de uma divergência entre a cultura dos colaboradores e aquela praticada pela universidade, corroborando novamente os resultados de estudos realizados por outros pesquisadores sobre a incompatibilidade do projeto de organização proposto pelas instituições públicas em geral com relação aos seus servidores. Essa situação requer uma atenção especial por parte da universidade, porque, se a organização não atende aos interesses das pessoas, ela não está cumprindo plenamente com a sua função social, principalmente pelo fato de ela ser uma organização pública, onde a legislação preconiza a satisfação do cidadão como um dever do ente público. Em vista disso, fica evidente a falta de coesão na política de gestão de pessoas, na qual a estratégia adotada pela instituição (ou imposta pelo sistema público) proporciona barreiras ao desenvolvimento pessoal e profissional dos trabalhadores.

Embora a natureza da instituição seja bastante complexa, o desafio imposto à universidade seria a adoção de uma política de gestão em recursos humanos de caráter mais democrático e alinhado aos anseios dos colaboradores, que utilizasse frequentemente instrumentos de diagnóstico organizacional a fim de (re)conhecer e suprir as reais necessidades humanas no ambiente de trabalho, além de fomentar uma distribuição de tarefas adequada às competências pessoais, de modo a instigar o trabalho em equipe, a busca por novos desafios e uma menor formalidade nas relações interpessoais, conforme os preceitos da Cultura Atena, proposta pelos funcionários.

É importante ressaltar a existência de uma atmosfera positiva no DERCA/UFSM em relação à vontade das pessoas em se adaptar a inovações. Os servidores demonstram ter ciência da necessidade de se atender às constantes exigências do ambiente onde a instituição está inserida, o que facilitaria a busca pelo alinhamento da cultura organizacional e, como consequência, influenciaria a qualidade dos serviços prestados.

Como sugestão para estudos futuros, recomendar-se-ia a realização de um estudo em toda a UFSM ou em outras instituições dessa natureza, o que poderia contribuir para o desenvolvimento de novos estudos sobre cultura nessa área, bem como de políticas públicas voltadas à qualidade de vida no trabalho e ao ensino público brasileiro. 


\section{REFERÊNCIAS BIBLIOGRÁFICAS}

CASTOR, B. V.; JOSÉ, H. A. A. Reforma e contra-reforma: a perversa dinâmica da administração pública brasileira. Revista de Administração Pública, Rio de Janeiro, v. 32, n. 6, p. 97-111, nov./dez. 1998.

CHATMAN, J. A. Improving international organizational research: a model of personorganization fit. Academy of Management Review, v. 14, n. 3, p. 333-349, 1989.

CODA, R. Psicodinâmica da vida organizacional: motivação e liderança. 2. ed. São Paulo: Atlas, 1997.

ESTRADA, R. J. S. O processo de planejamento estratégico e cultura organizacional das instituições públicas de ensino superior. In: ENCONTRO NACIONAL DE ENGENHARIA DE PRODUÇÃO, 21., ., 2001, Salvador. Anais... Salvador, 2001. 1 CD-ROM.

FLEURY, M. T.; FISCHER, R. M. Cultura e poder nas organizações. São Paulo: Atlas, 1989.

FREITAS, M. E. Cultura organizacional: formação tipologias e impactos. São Paulo: Makron, 1991.

GOMIDE JÚNIOR, S.; MARTINS, M. C. F. Os deuses da administração: construção e validação de quatro escalas para medida de cultura organizacional. Psicologia: teoria e pesquisa, v. 13, n. 3, set./dez. 1997.

GUIMARÃES, T. A. A nova administração pública e a abordagem da competência. Revista de Administração Pública, Rio de Janeiro, v. 34, n. 3, p. 125-140, maio/jun. 2000.

HANDY, C. Deuses da administração: como enfrentar as constantes mudanças da cultura empresarial. São Paulo: Saraiva, 1994.
NORBERTO, E. Cultura organizacional e diversidade cultural. In: ENCONTRO DE ESTUDOS MULTIDISCIPLINARES EM CULTURA, 5., 2009, Salvador. Anais... Salvador, 2009. 1 CD-ROM.

PINHEIRO, M. O princípio da eficiência na administração pública e o cidadão. Jus Navigandi, Teresina, ano 5, n. 40, mar. 2000. Disponível em: <http://jus.uol.com.br/revista/ texto/341>. Acesso em: 29 jul. 2011.

PIRES, J. C. S.; MACEDO, K. B. Cultura organizacional em organizações públicas no Brasil. Revista de Administração Pública, Rio de Janeiro, v. 40, n. 1, p. 81-105, jan./fev. 2006.

RIZZATTI, G. Categorias de análise de clima organizacional em universidades federais brasileiras. 2002. 215 f. Tese (Doutorado em Engenharia de Produção e Sistemas)Universidade Federal de Santa Catarina, Florianópolis, 2002.

UNIVERSIDADE FEDERAL DE SANTA MARIA. Regimento geral da UFSM (1988) - Adaptado. Disponível em: <http://sucuri.cpd.ufsm.br/ _pdf/docs/regimentog88.pdf $>$. Acesso em: 24 jun. 2011.

TERENCE, A. C. F.; ESCRIVÃO FILHO. E. Abordagem quantitativa, qualitativa e a utilização da pesquisa-ação nos estudos organizacionais. In: ENCONTRO NACIONAL DE ENGENHARIA DE PRODUÇÃO, 26., 2006, Fortaleza. Anais... Fortaleza, 2006. 1 CDROM.

VERGARA, S. C. Projetos e relatórios de pesquisa em administração. São Paulo: Atlas, 2006. 